\title{
Assessment of knowledge, attitude and practice of healthcare workers towards Hepatitis B virus infection in Mogadishu, Somalia: A Cross-Sectional Study
}

Ayan Aden Moussa ( $\square$ rahmajabane123@simad.edu.so )

SIMAD University https://orcid.org/0000-0002-4657-8081

Abdkeren Abdullahi Abdi

SIMAD University

Sharif Alhassan Abdullahi

Bayero University Kano

Research article

Keywords: Knowledge, attitude, practice, healthcare workers, Hepatitis B

Posted Date: February 14th, 2020

DOl: https://doi.org/10.21203/rs.2.23628/v1

License: (c) (1) This work is licensed under a Creative Commons Attribution 4.0 International License.

Read Full License 


\section{Abstract}

Background Hepatitis B virus (HBV) infection is globally distributed with its attendant complications such as chronic hepatitis, liver cirrhosis and hepatocellular carcinoma. Somalia is among the countries with high prevalence of HBV infection. This study aims to assess the knowledge, attitude and practice (KAP) of healthcare workers (HCW) towards HBV infection in Mogadishu, Somalia. Methods The cross-sectional study was conducted on HCW to assess KAP towards HBV infection. Standardized questionnaires were distributed to $470 \mathrm{HCW}$ recruited for the study from five hospitals. Data for demographic characteristics were described using percentages. Scores for KAP were presented as mean \pm standard deviation. MannWhitney $U$ and Kruskal-Wallis tests were used deduce inferences between the mean KAP and demographic characteristics of the participants. Spearman's rho correlation was used to determine any association between the KAP of the HCW. Results Of the 470 distributed questionnaire, 430 questionnaires were returned with a response rate of $91.5 \%$. Majority $(73 \%)$ of the participants had tertiary education. The mean scores for KAP were $16.3 \pm 4.4,6.9 \pm 0.4,7.03 \pm 1.5$ respectively. Significant ( $\mathrm{P}<0.01$ ) positive correlation between the KAP variables were observed. Professional cadre and marital status were found to be associated with mean KAP $(P<0.001)$. Conclusion This study revealed an acceptable level of KAP among the HCW and a potential source of participants for awareness campaign against HBV infection in Somalia.

\section{Background}

Hepatitis B infection (HBV) is still of global concern because of increase in prevalence [1]. Although the prevalence of HBsAg varies globally and classified as low, intermediate and high, more than 420 million people living as chronic carriers that constitute almost $7 \%$ of the world population $[2,3]$. The complications of HBV infection include acute and chronic infection, liver cirrhosis and hepatocellular carcinoma. High prevalence of HBV infection was reported from various parts of Africa among different population groups [4-13]. Although there were some reports on the prevalence of HBV in Somalia in the past [14-18] there is limited recent literature on the prevalence of HBV infection in Somalia. The country is among the endemic areas with high prevalence of HBV infection [19].

Health care workers (HCW) are among the most vulnerable group with an increased risk of HBV infection $[20,21]$. The HCW are occupationally exposed to patients with HBV infection and this expose them to transmission through percutaneous injuries from needle or sharps, mucocutaneous contact with blood and other body fluid $[22,23]$. Reports from previous studies indicate that categories of HCW can be infected with HBV perhaps through occupational injuries [24]. Prevalence of HBV was reported among HCW [22, 25 - 30] and Medical Students [31, 32]. Incidences of HBV transmission from HCW to patients has been documented [33]. Earlier reports on HCW towards HBV infection indicated that HCW have poor KAP toward HBV infection with a wide disparity of knowledge among them [24, 34].

It therefore important to ensure that there is an adequate knowledge on the etiology and natural course of the HBV infection among the HCW especially in endemic areas like Somalia to prevent them from 
possible nosocomial infection and transmission of the HBV infection to the patients on the other hand, by the HCW. It is equally important for all categories of HCW to know how to prevent infection from and to the patients under their care as well as other contacts. Based on the forgoing, this study was designed to assess the healthcare workers' knowledge, attitude and practices towards HBV infection in selected hospitals in Mogadishu, Somalia.

\section{Methods}

\section{Study design and sample size}

The study is a questionnaire-based descriptive cross-sectional design to assess the knowledge, attitude and practices of HCW towards HBV infection. The target population were HCW that include doctors, nurses/midwives and laboratory staff from selected hospital in Mogadishu. Four hundred and seventy six HCW working in Jazira, Madina, Benadir, Yardameli and Dr Sumeit hospitals were recruited for the study through convenient sampling method. Staff lists were obtained from the authorities of the selected hospitals. The lists were cleaned to exclude those staff not in direct contact with patients, retirees and staff on leave. The included HCW were included in the study were the doctors, nurse/midwives and laboratory staff cadres that are on ground for the period of study from June 2019 to October 2019. Four hundred and seventy HCW were therefore recruited for the survey.

\section{Study instrument}

The instrument for this study was adopted and modified from earlier report [1]. It is a self-administered questionnaire consisting of 38 questions focusing on the knowledge, attitude and practices of HCW toward HBV infection. It was designed to consist of four sections with the first section focusing on the demographic data on gender, educational qualification, marital status and occupational category. Section two consists of 23 questions that address the knowledge of the HCW on HBV infection. Section three of the instrument consists of 7 question that address the issues related to attitudes of the HCW towards HBV infection. Section four addresses the issue related to practices by HCW toward HBV infection through 8 questions that are mainly related to prevention of the infection. The tool was designed in English language and was tested for internal consistency $(a=0.828)$ which falls within the normal range of 0 to 1 [35]. To ensure the acceptability and understanding of the questions, the tool was pre-tested among $10 \%$ of sample from the similar target population and the result was not included in the final report.

\section{Statistical analysis}

The demographic characteristics of the participants were described using descriptive statistics in terms of percentages and mean \pm standard deviation. The distribution nature of the continuous data was assessed using Shapiro-Wilk test [36]. Mann-Whitney U test and Kruskal Wallis test were used to derive statistical inferences. Pearson correlation coefficient was used to assess the relationship between the 
KAP variables. $\mathrm{P}<0.05$ was considered significant and data processing and statistical analysis was conducted using SPSS version 22.0.

\section{Results}

\section{Demographic characteristics}

Out of 470 distributed questionnaire, 430 questionnaires were returned with response rate of $91.5 \%$. From Table 1 below, out of the 430 staff that participated, $54.7 \%$ were males and $45.3 \%$ were females. Majority of the participant $(73.0 \%)$ attended tertiary institutions, $23.3 \%$ had only secondary level of education and $3.0 \%$ had primary level of education. Among the participants, $46.5 \%$ are married, $45.3 \%$ are singles while $7.0 \%$ and $1.2 \%$ are divorced and widow respectively. Regarding the professional cadre of the participants, $15.3 \%$ are doctors while $69.8 \%$ and $14.9 \%$ are nurses/midwives and laboratory staff respectively.

\section{Assessment of knowledge towards HBV infection}

The knowledge of the participants towards HBV infection was assessed through questions related to its etiology, transmission, clinical manifestations, treatment and complications (Table 2). The responses were recorded as either "Yes" or "No" that covered a range of 23 questions. This allowed for a scoring range of 23 maximum score and 0 minimum score. Participants with score of $\leq 12$ were considered to have poor knowledge while those with score of $>12$ have adequate knowledge. For the 430 participants, $348(80.9 \%)$ demonstrated good knowledge about HBV infection whereas $82(19.1 \%)$ of the participants were within the poor knowledge range (Table 2). This is evident in that, majority of the participants demonstrated high level of knowledge about the existence 345 (80.2\%) and etiology of HBV infection 404 (94.0\%). Answers that correspond to adequate knowledge about transmission of HBV infection are $82.3 \%, 62.8 \%, 53.7 \%, 84.2 \%, 84.2 \%$ and $94.0 \%$. Adequate knowledge of the sign and symptoms of the infection corresponds to $57.0 \%, 67.0 \%, 68.8 \%, 59.8 \%$ and $66.7 \%$. Participants demonstrated adequate knowledge of the complication of the HBV infection as indicated by $74.9 \%$ and $72.8 \%$. The overall mean knowledge score in this study was $16.3 \pm 4.4$.

\section{Assessment of attitudes towards HBV infection}

This survey assessed the attitudes of the healthcare workers towards HBV infection based on 7 questions (Table 3). Each of the questions can either be positive or negative with scores of 1 or 0 respectively. Maximum score is 7 and minimum score is 0 . The attitude towards HBV infection was positive if the score is $\geq 4$ or negative if $<4$. In this survey, majority of the participants 250 (58.1\%) think that they can never be infected with HBV. Some 220 (51.2\%) participants explained that they will be in fear when they learnt that they are infected with HBV. Majority of the participant $(70.2 \%)$ believed physicians will be their first contact when they have HBV infection. This attitude corresponds to their resolve to attend healthcare facility when they are infected with HBV and as soon as when the symptoms appear. The participants (42.5\%) also expressed fear of disease spread to their families. However, this survey demonstrated an overall positive attitude towards HBV infection with mean score of $6.9 \pm 0.4$. 


\section{Assessment of practices towards HBV infection}

This survey assessed the HCW's practices towards HBV infection. In this regard, 8 questions related to screening, vaccination, precaution measures, and health education were assessed (Table 4). A good practice was considered to have a score of 1 and a bad practice had a score of 0 . The overall score range was between 8 as maximum, and 0 as minimum. A score of $\geq 4$ was considered as a good practice whereas score of $<4$ was a bad practice. In this survey, majority of the participants (83.7\%) were screened for HBV infection while $86.3 \%$ had vaccination against the infection. The survey further showed that precaution measures were curiously observed by the participants in which 410 (95.3\%) of them asked for new syringe before use, $379(88.1 \%)$ ensured that they use safe equipments for barbing, ear, and nose piercing. Majority of the participants (95.3\%) ensure that blood is screened before transfusion. Moreover, $88.2 \%$ of the participants declared that they would go for further investigations when they are diagnosed to have HBV infection. In addition, $80.2 \%$ of the participants revealed that they do not avoid meeting with HBV patients while vaccination against HBV infection was significantly considered by $86.0 \%$ of the participants as a preventive measure. This survey demonstrated an overall good practice toward HBV infection by the HCW with mean value of $7.03 \pm 1.5$.

The KAP assessment on education is statistically significant among the participants whereas only knowledge and practice were observed to be significantly different among the participants based on their marital status and professional cadre. However, there is no significant difference between the gender of the participants in association with KAP (Table 5).

\section{Correlation between the knowledge, attitude and practice}

The correlation between each two of the knowledge, attitude and practice was determination taken into consideration that $0-0.25$ is a weak correlation, $0.25-0.5$ is a fair correlation while $0.5-0.75$ is a good correlation and $>0.75$ was an excellent correlation. Significant positive correlation (Table 6 ) was obtained between Knowledge-attitude $(0.317, p<0.01)$ and knowledge-practice $(0.459, p<0.01)$. Although it is significant and positive, correlation between Attitude-practice is rather weak $(0.243, p<0.001)$.

\section{Discussion}

High burden of HBV infection reported among the HCW from the neighboring countries is so alarming and for the fact that $31.3 \%$ and $48.9 \%$ of the $\operatorname{HCW}[28,29]$ were found to be susceptible to HVB infection, the risk for contracting the infection may exceed the $10 \%$ chance among the HCW than the general population. In addition, HCW infected with HBV can also be source of infection to the patients as documented previously [37]. It is therefore essential to assess the KAP of HCW especially in endemic areas so as to emphasize on the use of universal guidelines [23] on prevention of infection transmission among the HCW from or to the patient. This study recorded a mean knowledge score to be $16.3 \pm 4.5$. High percentages of the participants have adequate knowledge on the etiology, clinical manifestation, treatment and complication of HBV infection. This is may be due to their education qualifications. It is also of concern that $46.3 \%$ of the participants are not aware that HBV infection can be transmitted 
through sexual intercourse. This may necessitate continue medical education for all categories of the $\mathrm{HCW}$ in the study hospitals. Inadequate knowledge of sexual transmission of HBV poses a continuous risk of infection spread among the population and strongly calls for strict pre-employment screening.

As regards the attitude of HCW in this study, the participants demonstrated positive attitude with a score of $6.9 \pm 1.2$ that within the average for this study. Evident to this is the fact that $58.1 \%$ believed that they can be infected with HBV. This response may possibly be due to the HCW occupational exposure and of course their prior knowledge on the infection all of which will enable them observed proper attitude toward HBV infection. Fear attitude is the first reaction claimed by the majority of the participants (51.2\%) and this may be because of their level of knowledge on the complication of HBV infection. Feeling shame as a reaction expressed by $21.6 \%$ of the participants may be related to fear of stigmatization in the society [38 - 40]. As regards to health facility visitation, $70.2 \%$ of the participants believed that physicians would be their first contact. However, $57.0 \%$ of the participants also expressed their will to let their spouses know about their infection status if were diagnosed of HBV infection. This attitude would surely help to curb the continuous spread of the infection. Although, $49.8 \%$ of the participants believed they would go to health facility after three weeks of appearance of symptoms, $42.8 \%$ expressed a positive attitude to visit health facility as soon as they manifest the symptoms of HBV infection. However, it is of concern that, among the HCW, some are still engaged in self-treatment as claimed by $6.0 \%$ of the participants in this study. Moreover, the attitude of the participants as regards the diagnosis of HBV infection is fair having $28.3 \%$ regarding costs as reasonable. Fear of disease spread among the family members is the major concern and a positive attitude expressed by $42.5 \%$ of the participants. This will further strengthen the preventive measures both at working environment and at their homes.

Participants in this study showed good practice towards HBV infection with average practice $7.03 \pm 1.5$ falling within the range for this study. This is least expected among HCW by virtue of their occupation. Majority of the participants (83.7\%) in this study were screened for HBV and $86.3 \%$ had vaccination against the infection. Preventive measures towards HBV infection spread are closely observed by the participants. This is evident in their attitude and practicing safe injection policies, ensuring blood screening before transfusion, ready to go for further investigations when infected with HBV and usage of sterile equipments for barbing, ear and or nose piercing. These practices can be as a result of their prior knowledge on HBV infection that make them fully aware of the complications of the infection, awareness and practice of global precaution standard [41]. It is important to note here that stigmatization of patients with HBV is a common practice among many societies and medical students [1,32]. Evident to this is the overwhelming response by the participants in this study in which $80.2 \%$ claimed to avoid HBV patient. This practice is inappropriate among the HCW that are first contacts to patients. Such practices can be detrimental to the patient which can lead to continuous deterioration of the patient condition. However, awareness regarding vaccination among the participants of this study is rather commendable. This study revealed that $86.0 \%$ of the participants had vaccination against HBV infection. In contrast to a report by Hutin et al [42] who reported that only $18 \%$ of HCW in Africa are vaccinated against HBV infection. 
Overall, the findings of this study differ from a previous report of KAP among HCW in Ghana [34] and are strongly supported by the positive correlation between the three variables; knowledge, attitude and practice and based on this the safety of the HCW in the study area as well as that of the patients is very sure. These categories of HCW can be engaged in health education and awareness campaign for their immediate society and this will truly help to curb the menace of HBV infection especially in endemic area.

\section{Conclusion}

The findings in this study indicate an acceptable level of awareness of HBV infection among the HCW possibly because of their educational and occupational backgrounds. Campaigns on preventive measures against HBV infection especially in hospital settings should be a frequent activity such as during clinical meetings and continue medical education programs. Regular health education can be organized fortnightly targeting patients that patronize the hospitals and by extension to the nearby population.

\section{Limitations}

This study was restricted to only HCW that have direct contact with patients. However, other staff of the hospitals such as those in administrative offices, cleaners and securities were not involved and their KAP on HBV infection should also be of priority since they are part of the general population as well as working with other professional in the health sector. As this survey did not employed a probability sampling method, the outcome is not a representative of the KAP for all the HCW in Mogadishu, Somalia. This survey has given a hint on the level of awareness of the HBV infection and more expensive research will be conducted in future.

\section{Abbreviations}

HBV: Hepatitis B virus

HCW: Healthcare workers

KAP: knowledge, attitude and practice

\section{Declarations}

\section{Acknowledgments}

We kindly thank the team at the Faculty of Medicine and Health Science, SIMAD University for their support in data preparation.

\section{Funding}


This research project was supported by the Centre for Research and Development (CRD), (CRD, grant no. SU-DA-RGL-2019-001). The funder had no role in study design, data collection, analysis, decision to publish, interpretation of data or preparation of the manuscript.

\section{Availability of data and materials}

The data supporting the conclusions of this article is included within the article.

\section{Corresponding author}

Correspondence to Ayen Aden Moussa, rahmajabane123@simad.edu.so.

\section{Author's contribution}

AAM, AAA and SAA conceived and designed the study. AYM and AAA conducted the survey. AAM, AAA and SAA analyzed the results. SAA draft the manuscript. AAM, AAA and SAA revised the manuscript. AAM, AAA and SAA read and approved the final version of the manuscript. all authors have read and approved the manuscript

\section{Competing interest}

The authors declare that they have no competing interests.

\section{Consent for publication}

Not applicable.

\section{Ethics and consent to participate}

The study was approved by the Ethics Committee of the SIMAD University (reference number IMRSU/FMHS (FR18) P001). All potential respondents were contacted personally and thoroughly informed about the aim of the study, data processing, and the use of the data. Participation was voluntary and participants could refuse to participate.

\section{References}

1. ul Haq, N., Hassali, M. A., Shafie, A. A., Saleem, F., Farooqui, M., Aljadhey, H. A cross sectional assessment of knowledge, attitude and practice towards Hepatitis B among healthy population of Quetta, Pakistan. BMC Public Health, 2012, 12(1), 692. 2. Ott JJ, Stevens GA, Groeger J, Wiersma ST. Global epidemiology of hepatitis B virus infection: new estimates of age-specific HBsAg seroprevalence and endemicity. Vaccine. 2012, 30(12):2212-9. 3. MacLachlan JH, Cowie BC. Hepatitis B virus epidemiology. Cold Spring Harbor perspectives in medicine. 2015, 5(5): a021410. 4. André F. Hepatitis B epidemiology in Asia, the middle East and Africa. Vaccine. 2000, 18: S20-2. 5. Abebe A, Nokes DJ, Dejene A, Enquselassie F, Messele T, Cutts FT. Seroepidemiology of hepatitis B virus in Addis Ababa, Ethiopia: transmission 
patterns and vaccine control. Epidemiology \& Infection. 2003,1(1):757-70. 6. Suckling, R. M., Taegtmeyer, M., Nguku, P. M., Al-Abri, S. S., Kibaru, J., Chakaya, J. M, and Gilks, C. F. Susceptibility of healthcare workers in Kenya to hepatitis B: new strategies for facilitating vaccination uptake. Journal of Hospital Infection. 2006, 64(3): 271-277. 7. Gasim GI, Murad IA, Adam I. Hepatitis B and C virus infections among pregnant women in Arab and African countries. The Journal of Infection in Developing Countries. 2013, 7(08):566-78. 8. Mohammed Y, Sharif A, Dabo NT. Seroprevalence of HBsAg among patients with febrile illnessess in Murtala Muhammad Specialist Hospital, Kano, Nigeria. Bayero Journal of Pure and Applied Sciences. 2015, 8(1):19-23. 9. Zenebe Y, Mulu W, Yimer M, Abera B. Sero-prevalence and risk factors of hepatitis $B$ virus and human immunodeficiency virus infection among pregnant women in Bahir Dar city, Northwest Ethiopia: a cross sectional study. BMC infectious diseases. 2014, 14(1):118. 10. Zampino R, Boemio A, Sagnelli C, Alessio L, Adinolfi LE, Sagnelli E, Coppola N. Hepatitis B virus burden in developing countries. World journal of gastroenterology. 2015, 21(42):11941. 11. Shimelis T, Torben W, Medhin G, Tebeje M, Andualm A, Demessie F, Mulu A, Tegbaru B, Gebre-Selassie S. Hepatitis B virus infection among people attending the voluntary counselling and testing centre and anti-retroviral therapy clinic of St Paul's General Specialised Hospital, Addis Ababa, Ethiopia. Sexually transmitted infections. 2008, 84(1):37-41. 12. Tegegne D, Desta K, Tegbaru B, Tilahun T. Seroprevalence and transmission of Hepatitis B virus among delivering women and their new born in selected health facilities, Addis Ababa, Ethiopia: a cross sectional study. BMC research notes. 2014, 7(1):239. 13. Sharif AA, Dabo NT, Getso MI. Prevalence of malaria and hepatitis $B$ virus infection in febrile patients in Kano northwest Nigeria. International Journal of Current Research and Review. 2015, 7(9):61-5. 14. Sebastiani, A., Aceti, A., Paparo, B. S., Pennica, A., Ilardi, I., Bile, K., \& Mohamud, O. M. (1985). Hepatitis B virus circulation in three different villages of Somalia. Transactions of the Royal Society of Tropical Medicine and Hygiene. 1985, 79(2), 162-164. 15. Jama, H., Grillner, L., Biberfeld, G., Osman, S., Isse, A., Abdirahman, M, and Bygdeman, S. Sexually transmitted viral infections in various population groups in Mogadishu, Somalia. Sexually Transmitted Infections. 1987,63(5): 329-332. 16. Bile, K., Mohamud, O., Aden, C., Isse, A., Norder, H., Nilsson, L, and Magnius, $L$. The risk for hepatitis $A, B$, and $C$ at two institutions for children in Somalia with different socioeconomic conditions. The American Journal of Tropical Medicine and Hygiene. 1992, 47(3), 357364. 17. Bile, K. M., Aden, A., Lindberg, G., Nilsson, L., Lidman, K., Norder, H, and Magnius, L. Epidemiology of hepatitis B in Somalia: inference from a cross-sectional survey of serological markers. Transactions of the Royal Society of Tropical Medicine and Hygiene. 1987, 81(5), 824-828. 18. Nur YA, Groen J, Elmi AM, Ott A, Osterhaus AD. Prevalence of serum antibodies against bloodborne and sexually transmitted agents in selected groups in Somalia. Epidemiology and Infection. 2000, 124(1):137-41. 19. Hassan-Kadle MA. The Diagnostic Challenges, Possible Etiologies and Lack of Researches of Hepatocellular Carcinoma in Somalia. Open Journal of Gastroenterology. 2017, 7:115. 20. West, D. J. The risk of hepatitis B infection among health professionals in the United States: a review. The American Journal of the Medical Sciences. 1984, 287(2): 26-33. 21. Beltrami, E. M., Williams, I. T., Shapiro, C. N, and Chamberland, M. E. Risk and management of blood-borne infections in health care workers. Clinical Microbiology Reviews. 2000, 13(3): 385-407. 22. Braka F, Nanyunja M, Makumbi I, Mbabazi W, Kasasa S, Lewis RF. Hepatitis B infection among health workers in Uganda: evidence of the need for health worker protection. Vaccine. 2006, 24(47-48):6930-7. 23. Gunson RN, Shouval D, Roggendorf M, Zaaijer H, Nicholas H, Holzmann H, De 
Schryver A, Reynders D, Connell J, Gerlich WH, Marinho RT. Hepatitis B virus (HBV) and hepatitis C virus $(\mathrm{HCV})$ infections in health care workers $(\mathrm{HCWs})$ : guidelines for prevention of transmission of HBV and HCV from HCW to patients. Journal of Clinical Virology. 2003, 27(3):213-30. 24. Bakry SH, Mustafa AF, Eldalo AS, Yousif MA. Knowledge, attitude and practice of health care workers toward Hepatitis B virus infection, Sudan. International Journal of Risk and Safety in Medicine. 2012, 24(2):95-102. 25. Kondili, L. A., Ulqinaku, D., Hajdini, M., Basho, M., Chionne, P., Madonna, E., ... \& Rapicetta, M. Hepatitis B virus infection in health care workers in Albania: a country still highly endemic for HBV infection. Infection.2007, 35(2): 94. 26. Ganju, S. A., and Goel, A. Prevalence of HBV and HCV infection among health care workers (HCWs). The Journal of Communicable Diseases. 2000, 32(3), 228-230. 27. Leers, W. D., and Kouroupis, G. M. Prevalence of hepatitis B antibodies in hospital personnel. Canadian Medical Association Journal. 1975, 113(9): 844. 28. Ziraba AK, Bwogi J, Namale A, Wainaina CW, Mayanja-Kizza $H$. Sero-prevalence and risk factors for hepatitis B virus infection among health care workers in a tertiary hospital in Uganda. BMC Infectious Diseases. 2010, 10(1):191. 29. Mueller A, Stoetter L, Kalluvya S, Stich A, Majinge C, Weissbrich B, Kasang C. Prevalence of hepatitis B virus infection among health care workers in a tertiary hospital in Tanzania. BMC Infectious Diseases. 2015, 15(1):386. 30. Jadallah RI, Adwan GM, Abu-Hasan NS, Adwan KM. Prevalence of hepatitis B virus markers among high risk groups in Palestine. Medical Journal of Islamic World Academy of Sciences. 2005, 15(4):157-60. 31. Pido B, Kagimu M. Prevalence of hepatitis B virus (HBV) infection among Makerere University medical students. African Health Sciences. 2005, 5(2):93-8. 32. Al Asmari SA, Alnomsi SJ, Dahash FD, Aliasseri AW, Shehri AM, Alatawi FH, Mirghani WA. Knowledge, Attitude and Practice towards Hepatitis B Virus among Medical Students in Tabuk City, Saudi Arabia. The Egyptian Journal of Hospital Medicine. 2018,72(1):3776-80. 33. Harpaz, R., Von Seidlein, L., Averhoff, F. M., Tormey, M. P., Sinha, S. D., Kotsopoulou, K, and Shapiro, C. N. Transmission of hepatitis $B$ virus to multiple patients from a surgeon without evidence of inadequate infection control. New England Journal of Medicine. 1996, 334(9), 549-554. 34. Afihene MY, Duduyemi BM, Hannah-Lisa A, Khatib M. Knowledge, attitude and practices concerning Hepatitis B infection, among healthcare workers in Bantama, Ghana: a cross sectional study. International Journal of Community Medicine and Public Health. 2017, 2(3):244-53. 35. Santos, J. R. A. Cronbach's alpha: A tool for assessing the reliability of scales. Journal of Extension. 1999, 37(2), 1-5. 36. Ghasemi A, ZahediasI S. Normality tests for statistical analysis: a guide for non-statisticians. International Journal of Endocrinology and Metabolism. 2012, 10(2):486. 37. Puro, V., Scognamiglio, P, and Ippolito, G. HIV, HBV, or HCV transmission from infected health care workers to patients. La Medicina del lavoro. 2003, 94(6): 556-568. 38. Wu H, Yim C, Chan A, Ho M, Heathcote J. Sociocultural factors that potentially affect the institution of prevention and treatment strategies for hepatitis B in Chinese Canadians. Canadian Journal of Gastroenterology and Hepatology. 2009, 23(1):31-6. 39. Rafique I, Saqib MA, Siddiqui S, Munir MA, Qureshi H, Javed N, Naz S, Tirmazi IZ. Experiences of stigma among hepatitis B and C patients in Rawalpindi and Islamabad, Pakistan. EMHJ-Eastern Mediterranean Health Journal. 2014, 20(12):796803. 40. Hassanpour Dehkordi A, Mohammadi N, NikbakhatNasrabadi A. Hepatitis-related stigma in chronic patients: A qualitative study. Applied Nursing Research. 2016, 29:206-10. 41. Sadoh, W. E., Fawole, A. O., Sadoh, A. E., Oladimeji, A. O, and Sotiloye, O. S. (2006). Practice of universal precautions among healthcare workers. Journal of the National Medical Association. 2006, 98(5): 722. 42. Hutin, Y., 
Hauri, A., Chiarello, L., Catlin, M., Stilwell, B., Ghebrehiwet, T, and Garner, J. Best infection control practices for intradermal, subcutaneous, and intramuscular needle injections. Bulletin of the World Health Organization. 2003, 81:491-500.

\section{Tables}

Due to technical limitations the tables are available as a download in the Supplementary Files.

\section{Supplementary Files}

This is a list of supplementary files associated with this preprint. Click to download.

- Tables.pdf

- STROBEchecklist.pdf 